\title{
Evaluasi Investasi Pendirian Cabang Usaha Dagang Lilin Bersinar
}

\author{
Devina Danayanti ${ }^{1}$ \\ Fakultas Ekonomi dan Bisnis \\ Universitas Udayana, Indonesia
}

\author{
I Putu Sudana ${ }^{2}$ \\ Fakultas Ekonomi dan Bisnis \\ Universitas Udayana, Indonesia
}

Surel : devinadanayanti7@gmail.com

ABSTRAK

Tujuan penelitian ini adalah untuk mengetahui kinerja riil outlet Antasura sesuai dengan studi kelayakan investasi dengan melakukan penilaian kembali terhadap proyek yang sedang berjalan untuk dapat mengetahui ketepatan estimasi masa lalu, dan untuk memastikan bahwa sumber-sumber ekonomi perusahaan digunakan sebaik-baiknya. Penelitian ini dilakukan di Perusahaan UD. Lilin Bersinar. Jenis data yang digunakan dalam penelitian ini adalah kualitatif berupa sejarah perusahaan, struktur organisasi perusahaan, dan izin usaha perusahaan dan kuantitatif berupa proceeds dan nilai investasi awal perusahaan. Teknik analisis yang digunakan yaitu membandingkan antara laporan studi kelayakan dan post audit dengan menggunakan metode capital budgeting Hasil analisis menunjukkan realisasi payback period sebesar 2,362 tahun, ARR sebesar 22,32 persen, NPV sebesar Rp.887.136.380, IRR sebesar 13,21 persen dari laporan studi kelayakan di UD.Lilin Bersinar.

Kata Kunci: Investasi; Post-audit; Capital Budgeting.

\section{Evaluation of Investment in Establishing Candlelight Trading Business Branch}

\section{ABSTRACT}

The purpose of this study is to determine the real performance of Antasura outlets in accordance with an investment feasibility study by reassessing ongoing projects to be able to determine the accuracy of past estimates, and to ensure that the company's economic resources are used as well as possible. This research was conducted at UD. Lilin Bersinar. The type of data used in this study is qualitative in the form of company history, company organizational structure, and business license and quantitative in the form of proceeds and initial investment value of the company. The analysis technique used is comparing the feasibility study report and post audit using the capital budgeting method. The results of the analysis show the realization of a payback period of 2,362 years, ARR of 22.32 persent, NPV of Rp.887,136,380, IRR of 13.21 Persent of feasibility study report at UD. Lilin Bersinar.

Keywords: $\quad$ Investment; Post-audit; Capital Budgeting.

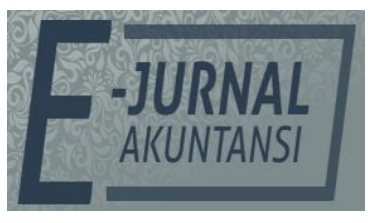

e-ISSN 2302-8556

Vol. 31 No. 9

Denpasar, September 2021 Hal. 2367-2377

DOI:

10.24843/EJA.2021.v31.i09.p17

PENGUTIPAN:

Danayanti, D., \& Sudana I.P. (2021). Evaluasi Investasi Pendirian Cabang Usaha Dagang Lilin Bersinar. EJurnal Akuntansi, 31(9), 2367 -

2377

RIWAYAT ARTIKEL: Artikel Masuk: 17 Mei 2020

Artikel Diterima: 20 September 2021

Artikel dapat diakses : https://ojs.unud.ac.id/index.php/Akuntansi/index 


\section{PENDAHULUAN}

Pada dasarnya investasi merupakan kegiatan penempatan dana pada aset tertentu pada periode tertentu dengan harapan memperoleh imbal hasil yang diinginkan (Sky \& Darmawan, 2017). Dalam setiap program investasi yang dilakukan, perusahaan berusaha memperoleh keuntungan yang optimal untuk dapat menjaga kelangsungan hidup dan mengembangkan usaha ditengah-tengah persaingan yang ketat. Manajemen perusahaan harus mengantisipasi segala kemungkinan dalam menentukan strategi baik dalam jangka pendek, jangka menengah, dan jangka panjang. Manajemen memerlukan infomasi, baik berupa informasi kualitatif dan informasi kuantitatif sebagai dasar pengambilan keputusan. Pengambilan keputusan selalu berupa pemilihan alternatif, dan pemilihan alternatif selalu mengandung ketidakpastian.

Informasi berperan penting sebagai pengurang ketidakpastian, sehingga manajemen dapat menganalisa dan memilih alternatif terbaik. Manajemen memerlukan informasi akuntansi manajemen berupa total nilai asset, total pendapatan, dan total biaya masa yang akan datang (Mulyadi, 2001). Keputusan investasi menjadi salah satu keputusan penting untuk entitas bisnis karena secara langsung mempengaruhi kelangsungan hidup bisnis mereka dan kesuksesan jangka panjang (L et al., 2015).

Pengambilan keputusan investasi menjadi bagian yang sangat penting bagi setiap entitas bisnis. UD. Lilin Bersinar juga mengalami situasi yang sama. Didirikan pada tahun 1998 oleh bapak Ir. I Ketut Mudana. Saat ini pemilik memiliki dua outlet yang dua-duanya terletak di Kota Denpasar. Outlet pertama merupakan outlet pusat yang telah berdiri sejak tahun 1998, outlet ini berlokasi di Jalan Tegal Wangi 31, Sesetan, Denpasar Selatan dengan luas area sebesar 335m². Outlet kedua berlokasi di Jalan Antasura 28D, Peguyangan Kangin, Denpasar Utara dengan luas area sebesar $330 \mathrm{~m}^{2}$ yang mulai beroperasi pada Juli 2018. Outlet in merupakan hasil dari sebuah keputusan investasi yang ditujukan untuk pengembangan bisnis. Tabel 1, menyajikan data penjualan pada kedua outlet UD. Lilin Bersinar.

Tabel 1. Data Penjualan Outlet UD. Lilin Bersinar Tahun 2013-2018 (dalam Rp)

\begin{tabular}{ccc}
\hline Tahun & Outlet Sesetan & Outlet Antasura \\
\hline 2013 & 37.588 .695 .660 & - \\
2014 & 42.888 .576 .252 & - \\
2015 & 51.025 .476 .744 & - \\
2016 & 57.937 .886 .699 & - \\
2017 & 64.594 .281 .512 & - \\
2018 & 73.402 .591 .080 & 66.062 .331 .972
\end{tabular}

Sumber: UD. Lilin Bersinar, 2020

Tabel 1, menunjukkan penjualan UD. Lilin Bersinar tahun 2013-2018. Terlihat bahwa penjualan UD. Lilin Bersinar mengalami peningkatan setiap tahunnya. Walaupun outlet didirikan pada masa krisis waktu itu namun secara perlahan dan pasti UD. Lilin Bersinar memperlihatkan perkembangannya dan berhasil mendirikan outlet keduanya, yakni outlet Antasura. Keputusan-keputusan investasi pembukaan outlet baru sangat mungkin dilakukan pada masa-masa yang akan datang. 
Berinvestasi atau mendirikan sebuah proyek tentulah membutuhkan dana yang cukup besar dan biasanya tingkat pengembaliannya pun memerlukan waktu yang cukup lama. Pengusaha sendiri yang harus dapat mempertimbangkan, meminimalisir dan menghidari setiap resiko yang mungkin timbul terhadap investasi yang dilakukan. Studi kelayakan proyek diperlukan sebagai alat bantu yang memudahkan para pemilik perusahaan/pengusaha agar dapat lebih mudah mengambil sikap dan keputusan-keputusan pelaksanaan investasi supaya resiko kegagalan dapat dihindari atau dikurangi. Studi kelayakan proyek investasi tersebut dapat melakukan penilaian investasi dengan menggunakan analisis proyek pada berbagai aspek.

Menurut Supriyono (2001), terdapat 5 (lima) tahapan dalam pengambilan keputusan investasi yaitu, identifikasi proyek investasi yang potensial, penaksiran manfaat dan biaya suatu proyek, penilaian usulan proyek (evaluasi proyek), penyusunan anggaran kebutuhan dana untuk investasi, dan penilaian kembali terhadap proyek (post audit). Berdirinya outlet Antasura dapat dipahami sebagai hasil dari telah diadopsinya tahapan-tahapan keputusan investasi tersebut, terutama langkah pertama sampai dengan tahapan keempat. Satu tahap terakhir masih sangat penting untuk dilakukan yaitu penilaian kembali tahapan proyek (post-audit).

Studi ini dilakukan untuk menjawab langkah kelima tersebut. Sebagai outlet baru, penting untuk melakukan post-audit investasi outlet Antasura ini. Dalam studi ini, tahap post-audit atas outlet baru ini dikaji sebagai sebuah studi kasus. Studi ini dibatasi hanya pada penilaian kembali kelayakan investasi berdasarkan metode-metode penilaian kelayakan investasi. Post audit memiliki dua manfaat penting yaitu penilaian kembali terhadap proyek yang sedang berjalan dapat untuk mengetahui ketepatan estimasi masa lalu, dan untuk memastikan bahwa sumber-sumber ekonomi perusahaan digunakan sebaik-baiknya. Suatu proyek yang sudah diterima harus ditinjau secara periodik untuk menentukan apakah keputusan investasi yang dipilih tersebut telah mencapai harapan yang awalnya telah ditentukan.

Metode yang dapat digunakan dalam menilai kelayakan investasi dan postaudit dipelajari sebagai masalah-masalah dalam capital budgeting. Alexandri (2008) menyatakan bahwa capital budgeting merupakan keseluruhan proses perencanaan dan pengambilan keputusan mengenai dana dimana jangka waktu kembalinya dana tersebut melebihi waktu satu tahun. Penganggaran modal ini merupakan konsep investasi karena melibatkan pengikatan dana dimasa sekarang untuk memperoleh laba dimasa mendatang. Dalam capital budgeting diadakan suatu penilaian dengan menggunakan beberapa teknik, sehingga dapat diambil keputusan apakah sebaiknya menerima atau justru menolak suatu rencana investasi (Kurniawati et al., 2014). Apa yang dirancang dalam capital budgeting penting untuk dievaluasi ketika investasi yang dianggap layak ini sudah benarbenar dijalankan.

Kasus yang terjadi dalam perusahaan ini adalah keputusan untuk menambah outlet baru yang telah diputuskan pada tahun 2018, dan saat ini sudah beroperasi selama satu tahun. Penting untuk dievaluasi apakah memang outlet ini sesuai atau tidak dengan yang direncanakan pada capital budgeting. Penilaian terhadap layak atau tidaknya suatu keputusan investasi dapat menggunakan 
metode payback periode (PP), Average Rate of Return (ARR), Net Present Value (NPV), dan Internal Rate of Return (IRR). Terdapat beberapa penelitian terdahulu yang juga menggunakan metode capital budgeting diantaranya (Maulana \& Putri, 2019), (Sky \& Darmawan, 2017), (Kurniawati et al. 2014), (Afriyen, 2012), (Vivianie et al., 2015), dan (Ribudiningsih et al. 2017).

Keputusan capital budgeting oleh suatu perusahaan yang nantinya akan menentukan arah strategis, karena pergerakan kearah produk, layanan, atau pasar yang baru harus diawali dengan pengeluaran modal terlebih dahulu. Capital budgeting sangat penting bagi perusahaan karena didalamnya terdapat jumlah biaya yang besar sedangkan manfaatnya baru dapat dinikmati dalam jangka panjang. Keputusan di capital budgeting ini akan memiliki pengaruh yang besar terhadap perkembangan perusahaan di masa yang akan datang. Walaupun perusahaan sudah melakukan prosedur capital budgeting, ketika ingin mendirikan cabang baru evaluasi atas ketepatan proses itu menjadi penting. Permasalahan yang dihadapi adalah kinerja UD. Lilin Bersinar sesuai dengan studi kelayakan investasi.

\section{METODE PENELITIAN}

Dalam penelitian ini menggunakan pendekatan kuantitatif. Data kuantitatif yang digunakan adalah laporan keuangan perusahaan. Dalam penelitian ini akan dilakukan penilaian kembali terhadap proyek (post audit) terhadap outlet yang sedang berjalan untuk mengetahui ketepatan estimasi masa lalu, ketepatan estimasi masa lalu bermanfaat untuk membuat estimasi baru atau estimasi yang lebih tepat terhadap usulan proyek yang baru. Dan juga post audit penting dilakukan untuk memastikan bahwa sumber-sumber ekonomi perusahaan digunakan sebaik-baiknya, jika suatu saat terjadi penyimpangan agar dapat diketahui dan dikoreksi dengan cepat. Metode yang digunakan dalam penelitian adalah capital budgeting.

Penelitian dilakukan pada cabang UD. Lilin Bersinar yaitu outlet Antasura yang berlokasi di Jl. Antasura 28D, Peguyangan Kangin, Denpasar Utara. Daerah Antasura adalah salah satu daerah strategis di denpasar, karena lingkungannya padat penduduk, dan untuk usaha yang sejenis jaraknya cukup jauh. UD. Lilin Bersinar cabang Antasura ini berdiri pada bulan Juli 2018.

Objek dalam penelitian ini adalah post audit outlet Antasura yang menggunakan metode capital budgeting, teknik yang digunakan yaitu Payback Period (PP) adalah jumlah tahun yang dibutuhkan suatu investasi akan bisa kembali (Brigham \& Houston, 2003). Data yang digunakan dalam perhitungan payback period adalah laporan investasi awal dan aliran kas tahunan (proceeds).

Average Rate of Return (ARR) merupakan suatu tingkat pengembalian (return) atau hasil yang diharapkan dari usulan investasi dan dinyatakan dalam suatu presentase. Data yang digunakan dalam perhitungan ARR adalah laporan investasi awal dan aliran kas tahunan (proceeds).

Net Present Value (NPV) merupakan selisih antara nilai sekarang arus kas masuk dan nilai sekarang arus kas keluar dari sebuah proyek (Hansen \& Mowen, 2017). Data yang digunakan dalam perhitungan NPV adalah biaya modal ratarata, laporan investasi awal, dan aliran kas tahunan (proceeds). 
Internal Rate of Return (IRR) merupakan tingkat diskon faktor yang menentukan nilai sekarang dari arus kas masuk proyek sama dengan nilai sekarang arus kas keluar proyek. Data yang digunakan dalam perhitungan IRR adalah laporan investasi awal dan aliran kas tahunan (proceeds).

Penelitian ini berfokus pada laporan perencanaan investasi perusahaan yang telah dibuat dengan penilaian kembali terhadap proyek (post audit) selama satu tahun berjalan dengan menggunakan metode capital budgeting. Teknik analisis data dalam penelitian ini yaitu membandingkan antara laporan studi kelayakan dan post audit dengan menggunakan metode capital budgeting, teknik yang digunakan yaitu.

Payback Period $=\frac{\text { Invetasi Awal }}{\text { Aliran kas tahunan }}$

Accounting Rate of Return $=\frac{\text { Laba akuntansi rata-rata }}{\text { Investasi }} \times 100 \%$

Net Present Value $=\left[\left(C F_{\mathrm{t}} /(1+\mathrm{i})^{\mathrm{t}}\right]-\mathrm{I}\right.$

Internal Rate of Return $=\mathrm{i}_{1}+\left(\frac{\text { Total DCF } i_{1}}{\text { Total DCF i1-Total DCF i2 }}\right) \times\left(i_{2}-i_{1}\right) \ldots$

\section{HASIL DAN PEMBAHASAN}

Data penelitian diperoleh dari laporan studi kelayakan dan laporan keuangan outlet Antasura pada tahun 2018.

Tabel 2. Investasi Awal Outlet Antasura Tahun 2018

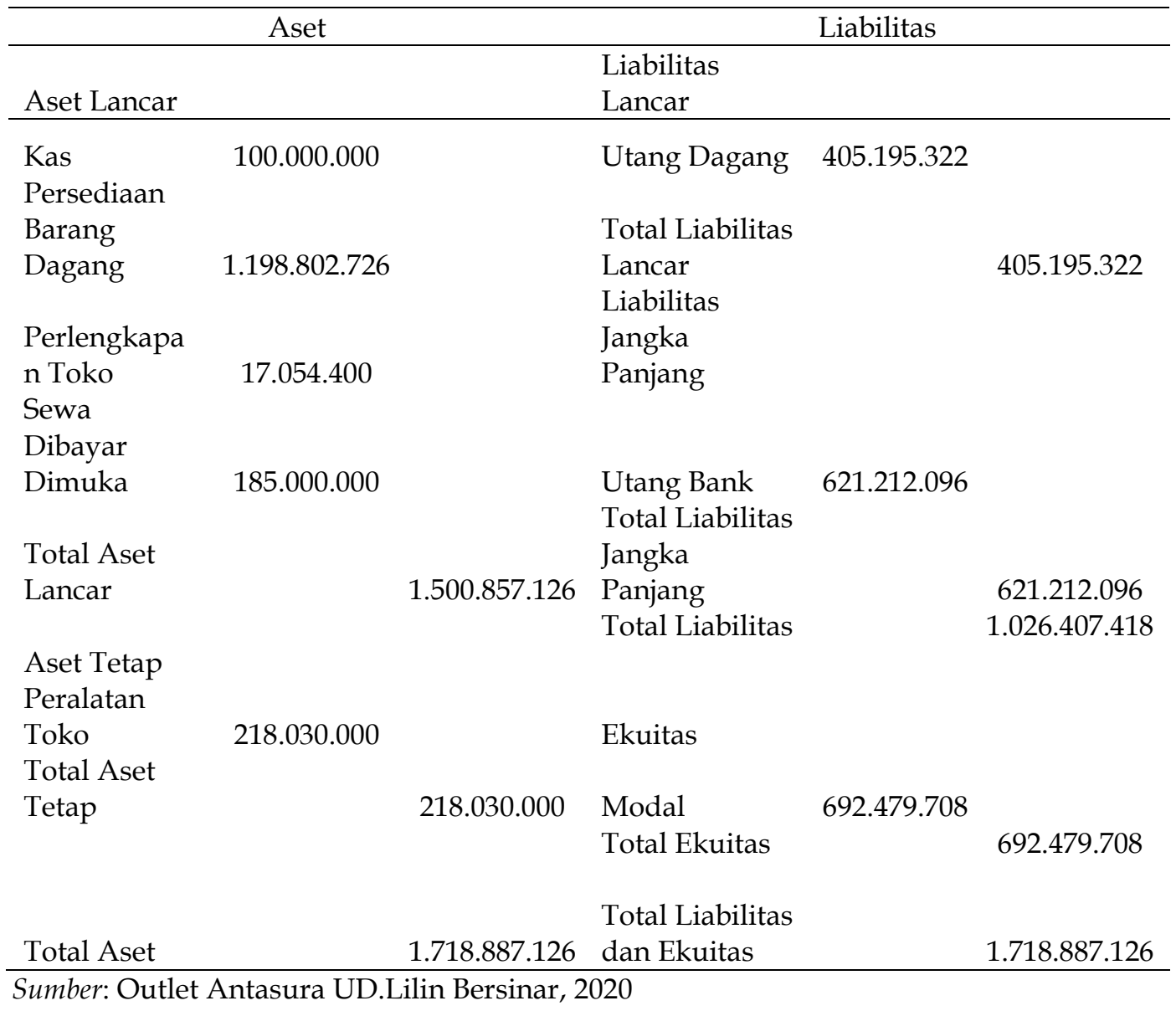


Sumber investasi perusahaan berasal dari modal sendiri berupa depsito dengan tingkat suku bunga bersih sebesar 4,8 persen dan utang bank dengan bunga sebesar 12 persen, dimana modal sendiri sebesar Rp. 692.479.708 dan utang bank sebesar Rp.1.026.407.418. Biaya modal rata-rata tertimbang (WACC) pada outlet Antasura yaitu sebagai berikut.

Tabel 3. Biaya Modal Rata-rata Tertimbang (WACC)

\begin{tabular}{lccc}
\hline \multicolumn{1}{c}{ Sumber Modal } & Komposisi & Biaya Modal & Rata-rata Tertimbang \\
& $(1)$ & $(2)$ & $(1) \times(2)$ \\
\hline Modal Sendiri & $40,29 \%$ & $4,8 \%$ & $1,93 \%$ \\
Utang Bank & $59,71 \%$ & $12 \%$ & $7,16 \%$ \\
Risiko & & $3 \%$ & $3 \%$ \\
Biaya Modal Rata-rata & Tertimbang (WACC) & $12,09 \%$ \\
\hline
\end{tabular}

Sumber: Data Penelitian, 2020

Hasil analisis investasi menurut laporan studi kelayakan outlet Antasura yang akan dijadikan sebagai pembanding post audit yaitu sebagai berikut, Hasil analisis payback period pada laporan studi kelayakan yaitu sebesar 2,667 tahun. Hasil analisis accounting rate of return pada laporan studi kelayakan yaitu sebesar 27 persen. Hasil analisis net present value pada laporan studi kelayakan yaitu sebesar Rp.911.168.369. Hasil analisis internal rate of return pada laporan studi kelayakan yaitu sebesar 21,2 persen.

Tabel 4. Laporan Laba/Rugi Outlet Antasura Tahun 2018

\begin{tabular}{lc}
\hline \multicolumn{1}{c}{ Pendapatan } \\
\hline Penjualan \\
Dikurangi: beban Pokok Penjualan & 66.062 .331 .972 \\
Laba Bruto & 64.733 .243 .363 \\
& \\
Beban Usaha & \\
Biaya Gaji & 379.297 .800 \\
Biaya Listrik & 30.000 .000 \\
Biaya Internet & 5.976 .000 \\
Biaya Kebersihan \& Keamanan & 3.000 .000 \\
Biaya Depresiasi Bangunan & 43.606 .000 \\
Biaya SKDU & 1.000 .000 \\
Biaya Perbaikan Gedung & 100.000 .000 \\
Biaya Sewa Bangunan & 37.000 .000 \\
Beban Bunga & 44.333 .300 \\
Biaya Pemasaran & 1.000 .000 \\
Total Beban Usaha &
\end{tabular}

Total Beban Usaha

645.213 .100

Laba Bersih

683.875 .509

Sumber: Outlet Antasura UD.Lilin Bersinar, 2020

Perhitungan proceeds:

Proceeds $=$ laba bersih + depresiasi

$=$ Rp. $683.875 .509+$ Rp. 43.606 .000

$=$ Rp. 727.481 .509

Perhitungan realisasi paybabck period di outlet Antasura didapat berdasarkan investasi awal perusahaan pada tahun 2018 sebesar Rp. 1.718.887.126 dibagi dengan proceeds pada tahun 2018 sebesar Rp. 727.481.509. Hasil perhitungan payback period di UD. Lilin Bersinar adalah 2,362 tahun. 
Pada laporan studi kelayakan outlet Antasura nilai payback period sebesar 2,667 tahun.

Accounting rate of return di outlet Antasura dilakukan dengan membandingkan tingkat pengembalian investasi yang diusulkan dengan tingkat pengembalian investasi yang ditetapkan. Pada laporan realisasi, investasi awal perusahaan pada tahun 2018 sebesar Rp. 1.718.887.126 tanpa nilai residu dan proceeds perusahaan selama 5 tahun sebesar Rp. 727.481 .509 dikali 5 yaitu Rp. 3.637.407.545. Dengan umur 5 tahun. Outlet Antasura menetapkan tingkat pengembalian akuntansi untuk usulan proyek sebesar 12,09 persen. Perhitungan tingkat pengembalian akuntansi adalah sebagai berikut.

Laba akuntansi rata-rata $=\frac{3.637 .407 .545}{5}-\frac{1.718 .887 .425}{5}=R p .383 .704 .024 / \mathrm{th}$

Tingkat pengembalian akuntanasi $=\frac{383.704 .024}{1.718 .887 .126} \times 100 \%=22,32 \%$

Jadi, nilai accounting rate of return pada laporan realisasi adalah sebesar 22,32 persen. Sedangkan pada laporan budgeting outlet Antasura nilai accounting rate of return sebesar 27 persen. Dengan tingkat diskonto sebesar 12,09 persen, maka realisasi nilai tunai proceeds dihitung sebagai berikut.

Tabel 5. Nilai Tunai Aliran Kas Bersih (dalam Rp)

\begin{tabular}{lccc}
\hline Tahun & $\begin{array}{r}\text { Proceeds } \\
(1)\end{array}$ & \multicolumn{2}{c}{ Faktor Diskonto (12,09\%) } \\
$(2)$ & \multicolumn{1}{c}{ PV } \\
$(1) \times(2)$
\end{tabular}

Sumber: Data Penelitian, 2020

Berdasarkan perhitungan pada Tabel 5, perhitungan nilai tunai proceeds bernilai lebih besar dari nilai investasi awal. Realisasi nilai Net Present Value (NPV) sebesar Rp. 897.136.380. Sedangkan pada laporan studi kelayakan nilai Net Present Value (NPV) sebesar Rp. 911.168. 369.

Internal Rate of Return (IRR) dilakukan dengan membandingkan tingkat pengembalian internal suatu proyek dengan tingkat pengembalian internal yang diinginkan oleh perusahaan. Perhitungan IRR di outlet Antasura dilakukan dengan langkah mencari suku bunga, dapat dihitung dengan investasi awal perusahaan pada tahun 2018 sebesar Rp. 1.718.887.126 dibagi dengan proceeds pada tahun 2018 sebesar Rp. 727.481.509 mendapatkan hasil 2,363. Karena umur investasi lima tahun, dengan demikian suku bunga yang berhubungan dengan 2,363 adalah 30 persen dan 32 persen. Setelah mendapatkan suku bunga, selanjutnya dilakukannya interpolasi dapat dilihat pada Tabel 6 .

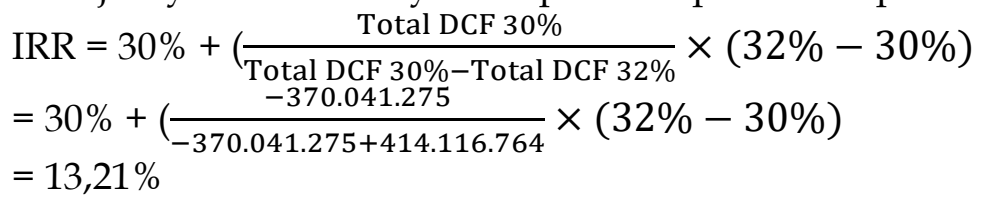

Realisasi nilai Internal Rate of Return (IRR) sebesar 13,21 persen. Sedangkan pada laporan studi kelayakan nilai Internal Rate of Return (IRR) sebesar 21,2 persen. 
Tabel 6. Discounted Cash Flow (DCF) (dalam Rp)

\begin{tabular}{llll}
\hline Tahun & \multicolumn{1}{c}{ PV } & \multicolumn{2}{c}{ Discounted Cash Flow (DCF) } \\
& \multicolumn{1}{c}{$30 \%$} & \multicolumn{1}{c}{$32 \%$} \\
\hline 0 & -1.718 .887 .126 & -1.718 .887 .126 & -1.718 .887 .126 \\
1 & 648.913 .506 & 499.164 .235 & 491.601 .141 \\
2 & 579.075 .281 & 342.648 .095 & 332.343 .481 \\
3 & 516.511 .871 & 235.098 .712 & 224.570 .379 \\
4 & 460.495 .795 & 161.232 .378 & 153.498 .598 \\
5 & 411.027 .053 & 110.702 .430 & 102.756 .763 \\
& Total & -370.041 .275 & -414.116 .764 \\
\hline
\end{tabular}

Sumber: Data Penelitian, 2020

Payback period (periode pengembalian) merupakan jumlah tahun yang dibutuhkan suatu investasi akan bisa kembali. Dapat diketahui bahwa besarnya payback period pada laporan budgeting outlet Antasura adalah sebesar 2,667 tahun, apabila dibandingkan dengan realisasi payback period tahun 2018 yaitu sebesar 2,362 tahun. Hal ini menunjukkan bahwa nilai periode pengembalian pada realisasi mendekati budgeting yang telah dibuat perusahaan. Dengan keadaan yang demikian, maka investasi yang dilakukan oleh perusahaan layak untuk dijalankan.

Accounting rate of return (tingkat pengembalian akuntansi) merupakan suatu tingkat pengembalian (return) atau hasil yang diharapkan dari usulan investasi dan dinyatakan dalam suatu presentase. Dapat diketahui bahwa besarnya accounting rate of return pada laporan budgeting outlet Antasura adalah sebesar 27 persen, apabila dibandingkan dengan realisasi accounting rate of return tahun 2018 yaitu sebesar 22,32 persen. Berdasarkan laporan realisasi tingkat pengembalian akuntansi mendekati laporan budgeting yang dilakukan sebelumnya. Dengan keadaan demikian, maka investasi yang dilakukan oleh perusahaan layak untuk dijalankan.

Net present value (NPV) adalah selisi antara nilai sekarang arus kas masuk dan nilai sekarang arus kas keluar dari sebuah proyek. Dapat diketahui bahwa besarnya NPV pada laporan budgeting outlet Antasura adalah sebesar Rp. 911.168.369, apabila dibandingkan dengan realisasi NPV tahun 2018 yaitu sebesar Rp. 897.136.380. Berdasarkan laporan realisasi tingkat pengembalian akuntansi mendekati laporan budgeting yang dilakukan sebelumnya. Dengan keadaan demikian, maka investasi yang dilakukan oleh perusahaan layak untuk dijalankan.

Pengambilan keputusan investasi dengan metode internal rate of return (IRR) dilakukan dengan membandingkan tingkat pengembalian internal suatu proyek dengan tingkat pengembalian internal yang diinginkan oleh perusahaan. Dapat diketahui bahwa besarnya IRR pada laporan budgeting outlet Antasura adalah sebesar 21,2 persen, apabila dibandingkan dengan realisasi IRR tahun 2018 yaitu sebesar 13,21 persen. Berdasarkan laporan realisasi tingkat pengembalian akuntansi mendekati laporan budgeting yang dilakukan sebelumnya. Dengan keadaan demikian, maka investasi yang dilakukan oleh perusahaan layak untuk dijalankan. 
Implikasi dari penelitian mencakup dua hal, yaitu implikasi teoritis dan implikasi praktis. Implikasi teoritis berhubungan dengan pemahaman mengenai keputusan investasi. Sedangkan implikasi praktis diharapkan memberikan tambahan informasi kepada perusahaan UD. Lilin Bersinar.

Hasil penelitian ini memberikan implikasi teoritis bagi perusahaan berdasarkan metode capital budgeting agar perusahaan dapat mengambil keputusan yang terbaik untuk perkembangan perusahaan dimasa yang akan datang. Sedangkan implikasi praktis dapat memberikan tambahan informasi kepada perusahaan didalam perhitungan capital budgeting.

\section{SIMPULAN}

Realisasi Payback Period (PP) di UD. Lilin Bersinar selama 2,362 tahun ternyata lebih cepat 0,305 dibandingkan dengan waktu yang ditetapkan. Realisasi Accounting rate of return (ARR) sebesar 22,32 persen ternyata lebih kecil dibandingkan pada laporan budgeting sebesar 27 persen, walaupun realisasi lebih kecil namun UD. Lilin Bersinar cabang Antasura layak melakukan investasi kembali karena nilai ARR lebih besar dari biaya modal rata-rata tertimbang perusahaan sebesar 12,09 persen.

Realisasi Net Present Value (NPV) sebesar Rp.897.136.380 ternyata lebih kecil dibandingkan dengan laporan budgeting sebesar Rp.911.168.369. Dari hasil tersebut maka layak untuk melakukan investasi kembali karena NPV positif menandakan bahwa investasi awal telah tertutupi dan tingkat pengembalian yang diperlukan telah terpenuhi.

Realisasi Internal Rate of Return (IRR) sebesar 13,21 persen ternyata lebih kecil dibandingkan dengan laporan budgeting sebesar 21,2 persen, walaupun realisasi nilai IRR lebih kecil namun perusahaan layak untuk melakukan investasi kembali karena IRR lebih besar dari biaya modal rata-rata tertimbang sebesar 12,09 persen.

Post-audit penting untuk dilakukan oleh UD. Lilin Bersinar, dengan dilakukannya post-audit kita dapat mengetahui ketepatan estimasi di masa lalu dan memastikan bahwa sumber-sumber ekonomi perusahaan digunakan dengan sebaik-baiknya. Dan hasil dari post-audit ini juga dapat digunakan UD. Lilin Bersinar untuk pertimbangan dalam mengembangkan usahanya di masa mendatang.

Berdasarkan hasil penelitian dan simpulan yang telah dijabarkan maka saran yang dapat diberikan yaitu UD. Lillin Bersinar harus melakukan post-audit sebelum mengambil keputusan untuk melakukan pendirian cabang kembali. Hal ini karena hasil dari post-audit akan memudahkan perusahaan dalam mengambil keputusan apakah perusahaan layak untuk melakukan investasi kembali atau lebih baik perusahaan mengembangkan investasi yang sedang berjalan saat ini.

\section{REFERENSI}

Abdullah, F. (2015). Analisis Kelayakan Investasi Aktiva Tetap Pembelian Mesin Printing Pada Pt . Radja Digital Printing Samarinda. EJournal Ilmu Administrasi Bisnis, 3(2), 297-310.

Adista, S. D., \& Moridu, I. (2019). Analisis Capital Budgeting Terhadap Kelayakan Investasi Aktiva Tetap Pada Pt. Kharisma Arta Abadi Guna Luwuk Kabupaten Banggai. Jurnal EMOR, 2(1). 
Afriyeni, E. (2012). Keputusan Investasi JJangka Panjang: Capital Budgeting. Polibisnis, 4(1), 65-75.

Arifianto, S. (2016). Implementasi Metode Penelitian Studi Kasus Dengan Pendekatan Kualitatif (Cetakan I). Aswaja Pressindo.

Alexandri, M. B. (2008). Manajemen Keuangan Bisnis (Cetakan Ke). Alfabeta.

Brigham, \& Houston. (2003). Fundamental of Financial Management (10th Editi). South Western College Pub.

Cahyosatrio, D. A., Dzulkirom, M., \& Saifi, M. (2014). Analisis Capital Budgeting Sebagai Salah Satu Metode Untuk Menilai Kelayakan Investasi Aktiva Tetap Mesin dan Kendaraan ( Studi Kasus pada Perusahaan Malang Indah ). Jurnal Administrasi Bisnis $S 1$ Universitas Brawijaya, 9(1), 80709.

Fitrah, M. (2018). Metode Penelitian: Penelitian Kualitatif, Tindakan Kelas \& Studi Kasus. CV Jejak (Jejak Publisher).

Hidayah, I., \& Ningsih, L. R. (2015). Implementation of Capital Budgeting for MSME in Fixed Assets Investment Decisions Through Andragogy Approachment. Scientific Journal of PPI-UKM, 2(5).

Husnan, S., \& Suwarsono. (2008). Studi Kelayakan Proyek (Edisi Keem). UPP AMP YKPN.

Ibrahim, Y. (2009). Studi Kelayakan Proyek (Edisi Revi). Rineka.

Jones, C. P. (2007). Investments: Analysis and Management. John Wiley \& Sons.

Kasmir, \& Jakfar. (2003). Studi Kelayakan Pengembangan Bisnis (Edisi Revi). Kharisma Putra Utama.

Kengatharan, L., \& Clamenthu, P. D. (2017). Use of Capital Investment Appraisal Practices and Effectiveness of Investment Decisions: A Study on Listed Manufacturing Companies in Sri Lanka. Asian Journal of Finance $\mathcal{E}$ Accounting, 9(2), 287.

Krisanti, N. P. R. (2012). Pengaruh Pengetahuan Akuntansi Dan Jiwa Kewirausahaan Terhadap Penggunaan Informasi Akuntansi Dalam Pembuatan Keputusan Investasi. E-Jurnal Akuntansi Universitas Udayana, 118.

Kurniawati, F. A., Darminto, \& Rahayu, S. M. (2014). Analisis Kelayakan Investasi Atas Rencana Penambahan Aktiva Tetap Dengan Menggunakan Teknik Capital Budgeting (Studi Pada Perusahaan Indah Cemerlang SingosariMalang). Jurnal Administrasi Bisnis (JAB), 8(2), 1-8.

Maulana, W., \& Putri, D. L. P. (2019). Analisis Kelayakan Investasi Sebagai Rencana Penggantian Mesin Dengan Teknik Capital Budgeting (Studi Pada Perusahaan Tegel Beton Dan Sanitair Warna Agung Pamekasan). Jurnal Ilmu Manajemen METHONOMIX, 2(1).

Ningsih, H. T. K., \& Diba, S. F. (2018). Analisis Capital Budgeting Dalam Meningkatkan Keputusan Investasi Pada Pt . Samudera Indonesia. Jurnal Riset Akuntansi Multiparadigma (JRAM), 5(1), 38-44.

Pamungkas, H. S., \& Puspaningsih, A. (2013). Pengaruh Keputusan Investasi, Keputusan Pendanaan, Kebijakan Dividen Dan Ukuran Perusahaan Terhadap Nilai Perusahaan. Jurnal Akuntansi \& Auditing Indonesia, 17(2), 155164.

Ribudiningsih, A., Rahayu, S. mangesti, \& Z.A, Z. (2017). Analisis Capital Budgeting Untuk Menilai Kelayakan Investasi Aktiva Tetap (Studi Kasus 
pada PT Citra Perdana Kendedes, Malang). Jurnal Administrasi Bisnis (JAB, 53(1), 157-166.

Sawang, M., \& Nurjanah, Y. (2019). Analisa Anggaran Dan Realisasi Dengan Metode Varians Terhadap Laporan Laba Rugi (Studi Kasus Pada Pt. J Darmawan Venture Capital).

Sky, M. D., \& Darmawan, A. (2017). Analisis Kelayakan Investasi Dengan Capital Budgeting Terhadap Proyek Battery Shop Di Pt. Indonesia Airasia. Jurnal Administrasi Bisnis S1 Universitas Brawijaya, 51(2), 32-39.

Vivianie, R. D., Darminto, \& Yaningwati, F. (2015). Analisis Kelayakan Investasi Usaha Berdasarkan Capital Budgeting Under Risk (Studi Pada Perusahaan Daerah Air Minum Kabupaten Banyuwangi). Jurnal Administrasi Bisnis S1 Universitas Brawijaya, 26(1), 86273.

Zattira, R., Jaka, D., \& Purnomo, E. (2016). Penganggaran Modal Dalam Pengambilan Keputusan Investasi Jangka Panjang. RELASI: Jurnal Ekonomi, 12(2). 